\title{
Cookies with Barbara
}

Cite as: CMAJ 2019 December 16;191:E1385-6. doi: 10.1503/cmaj.190464

sabella was a 13-year-old patient who had an extended stay in our intensive care unit (ICU). Complications of her chronic lung disease led her to need extracorporeal life support (also known as extracorporeal membrane oxygenation) as she waited for suitable lungs for transplantation. Unfortunately, she was a difficult match.

The ICU and the transplant teams developed a close relationship with the family. Isabella's mother Mary spent the most time at her bedside. The Pediatric ICU team invested a lot of time and effort caring for Isabella, week after week, day after day. As the intensivist on the team, I feel like the conductor of an orchestra: my job really depends on each team member who rounds every day at each bedside: trainees, nurses, respiratory therapists. Also clear is the importance of each ancillary health care professional: the dietician, the pharmacist, the child life specialists, the spiritual care provider and the physiotherapist. But it took Isabella's mother to show me that the ICU team is wider than I had ever imagined.

After five months in the ICU, Isabella was progressing with frequent episodes of sepsis and multiple organ dysfunction syndrome. No suitable lungs became available. We had many meetings with all parties about how to proceed. Stopping treatment at this stage was an extremely difficult decision for Mary; for our team, it was becoming more and more challenging to continue with inotropes and dialysis when the chances of surviving a transplant were increasingly slim. As a team, we were relieved when, after much dialogue, a decision was made jointly to remove Isabella from the transplant list and stop life support.

Throughout her stay, Isabella was free to have visitors whenever the family

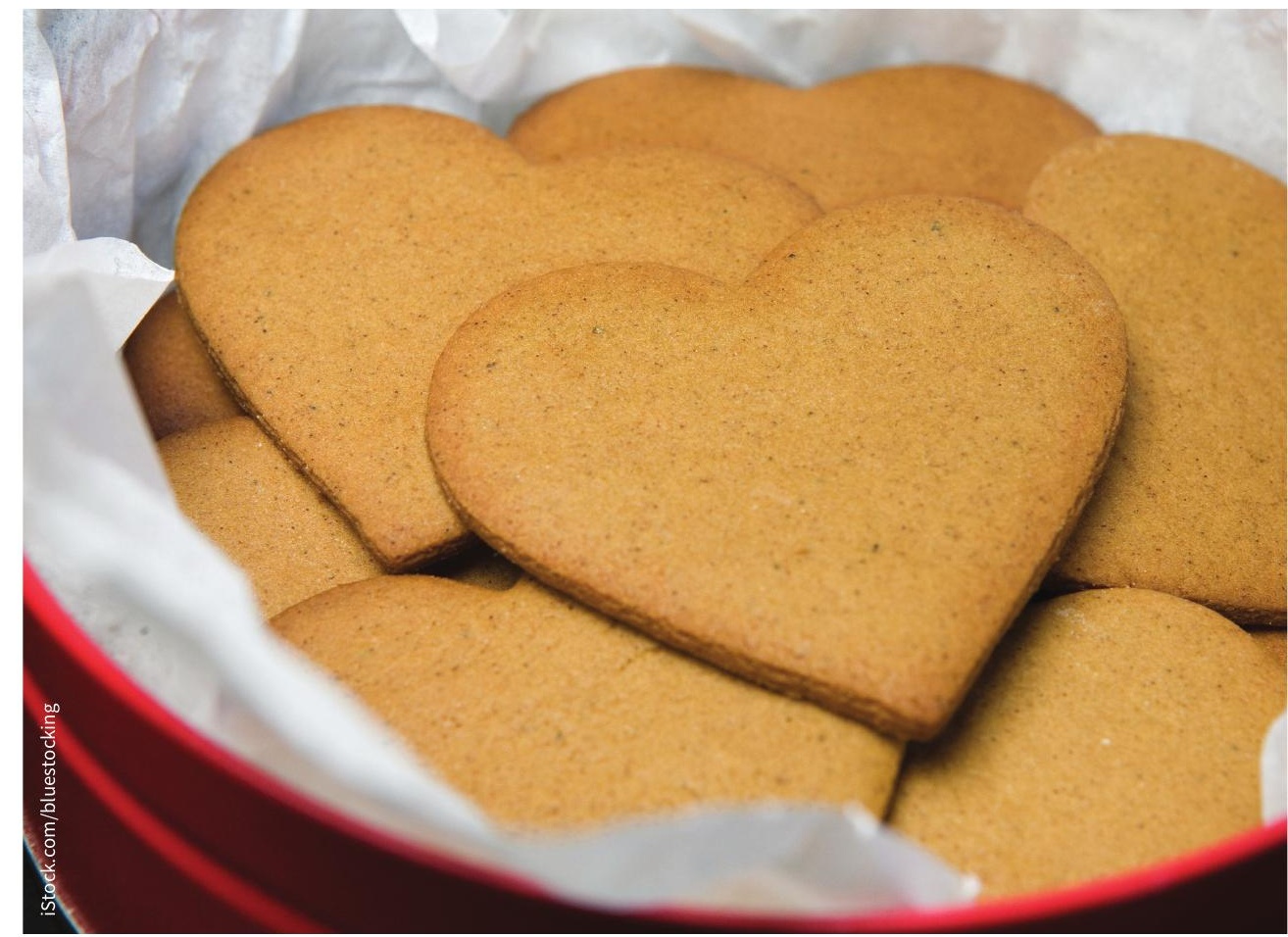

wanted. They made her room feel like home - it was filled with pictures, posters, cards and favourite stuffy animals. We made sure she always had good analgesia and sedation, and all the palliative care resources available while her acute treatment was still being provided. At the end, she was in a coma for a few weeks. On her final day, she was dressed in her favourite clothing. A religious ceremony was performed at the bedside, the monitors were dimmed, and the ICU team stood outside the room. Life support was stopped, blood lines were cut, and she was separated from the machine that had kept her alive for so long. Isabella died quickly but peacefully, in the presence of her loving family.

The morning after Isabella died, her mother returned to the ICU to talk to the staff about final arrangements to transfer
Isabella's body to her hometown. Mary wanted to thank and say goodbye to everyone who had become a part of her family. After being with us for five months, the bond that had developed required a proper farewell. Mary said that she had no regrets and that her family was grateful that we had tried everything possible to save her daughter.

As I entered the unit, Mary was there at the main desk, surrounded by some of the nursing staff. During the conversation, Mary said, "I would like to see Barbara. Does anyone know if she is here today?" Barbara is our main cleaning staff member in the ICU; a quiet, shy, lovely lady who speaks with a strong Greek accent.

"She was so kind to us," Mary said. "So many times she came to the room and did more than just cleaning. I want to tell her 
that she made a difference during so many difficult days and long nights."

Mary told us about the many occasions when Barbara would come in, gently and gracefully, to clean the room. Barbara would smile and then offer words of comfort and encouragement, expressing sympathy and concern. "She helped to us to keep going," Mary said. "Barbara would also bring a cup of tea and cookies for us." She paused for a moment, a wistful look was evident on her face. "This happened many, many times."

I searched the unit for Barbara, peering into rooms until I found her, head down, sweeping the floor as a patient dozed peacefully a few feet away. When I explained that Mary wanted to see her, I could see that she was holding back tears. Putting my arm over her shoulder, I walked back with her to where Mary was waiting. Both ladies gently stepped away from me and the rest of the nearby staff. Then they engaged in a warm conversation in one of the ICU alcoves for 10 minutes.

While they were talking, one of our trainees whispered to me, "I am not surprised by this." She described Barbara as one of her best "buddies" in the unit, the person who first welcomed her when she started in the ICU, and the one who supplies her with cookies during difficult nights on call. "Ah, and Barbara's cookies are the best," she added. Why Barbara's cookies were never mentioned in the fellowship program evaluations I really cannot explain!

Before Barbara and Mary parted, they exchanged hugs. As Mary headed back to the nursing station and Barbara back to her brooms and mops, I noticed tear stains on both their faces. Later, I found Barbara and gave her a hug myself to express gratitude for her work - work that went beyond the room cleaning and the wiping of beds and mattresses. We shared our sadness for Isabella and her family.

"She was so beautiful," Barbara said. "So young but so sick!"

I told Barbara that Mary had been consoled by the fact that everything possible had been done. "She was so grateful that everybody tried really, really hard to save her daughter," I said. I wanted her to know that "everybody" certainly included her, our staff member responsi- ble for keeping the ICU tidy and clean. I hope she did.

I left Barbara to her work. Walking slowly through the silent hospital corridor, I reflected on how many times I had passed empty rooms being cleaned by a crew after a patient had passed away. How many times had I missed this, had I failed to understand that they feel it, too; that they also have lost a patient?

On that sad Saturday morning, while still struggling with the loss of a patient, I discovered another partner in care, another extraordinary and engaged member of our ICU team.

\section{Daniel Garros MD}

Department of Pediatrics, Faculty of Medicine and Dentistry, University of Alberta, and Pediatric Intensive Care Unit, Stollery Children's Hospital, Edmonton, Alta.

This article has been peer reviewed.

This is a true story. The patient's mother and Barbara have given their consent for this story to be told. The names of the patient and her mother were changed. 